\title{
Configurações
}

Revista de sociologia

\section{A função do teatro no contexto do congelamento da cultura em São Paulo, Brasil}

The role of theatre in the context of the cultural freeze in Sao Paulo, Brazil La fonction du théâtre et de la situation de la culture congelée à São Paulo

\section{Rita Miranda}

\section{OpenEdition}

\section{Journals}

Edição electrónica

URL: http://journals.openedition.org/configuracoes/5695

DOI: $10.4000 /$ configuracoes.5695

ISSN: $2182-7419$

\section{Editora}

Centro de Investigação em Ciências Sociais

Edição impressa

Paginação: 70-82

ISSN: 1646-5075

\section{Refêrencia eletrónica}

Rita Miranda, « A função do teatro no contexto do congelamento da cultura em São Paulo, Brasil », Configurações [Online], 22 | 2018, posto online no dia 21 dezembro 2018, consultado o 24 abril 2019 URL : http://journals.openedition.org/configuracoes/5695; DOI : 10.4000/configuracoes.5695 
Miranda, Rita - A função do teatro no contexto do congelamento da cultura em São Paulo, Brasil. Configurações, vol. 22, 2018, pp. 70-82.

\title{
A função do teatro no contexto do congelamento da cultura em São Paulo, Brasil
}

\author{
RITA MIRANDA* \\ Doutoranda do CET - Centro de Estudos de Teatro na Faculdade de Letras da Universidade de Lisboa
}

\begin{abstract}
Resumo
O artigo analisa a condição atual dos grupos de teatro não comercial da cidade de São Paulo no contexto do recente congelamento parcial da verba pública destinada à cultura na gestão municipal do ano 2017. O texto busca enfatizar a relação do corte de orçamento com a atual crise política que acomete o Brasil, bem como os efeitos dessa crise dentro do universo do teatro da cidade, em que os grupos vêm perdendo seus espaços de trabalho. A reflexão se estende para o papel político do teatro e a ideia de consciente coletivo como algo ultrapassado que precisa ser retomado com urgência.
\end{abstract}

Palavras-chave: teatro, crise política, congelamento da cultura, São Paulo, coletivo.

\begin{abstract}
The role of theatre in the context of the cultural freeze in Sao Paulo, Brazil

The paper analyses the current conditions of non-commercial theatre groups in the city of Sao Paulo in the context of the partial public budget freeze destined to culture during the 2017 municipal management. The relation between budget cuts and the current political crisis in Brazil will be emphasised, as well as the effects of the crisis within the scope of city theatre, where groups have been losing their work space. The reflexion extends to the theatre's political role and the idea of a collective consciousness as something that has been surpassed, but that needs to be urgently resumed.
\end{abstract}

Keywords: theatre, political crisis, cultural freeze, Sao Paulo, collective.

\footnotetext{
Résumé

La fonction du théâtre et de la situation de la culture congelée à São Paulo, Brésil

L'article analyse l'état actuel des groupes de théâtre non commerciaux de la ville de São Paulo dans le cadre du récent gel partiel des fonds publics destinés à la culture dans la gestion municipale de l'année 2017. Le texte vise à souligner la relation entre

*E-mail: ritoca816@gmail.com
} 
la coupe budgétaire et la crise politique actuelle affectant le Brésil, ainsi que les effets de cette crise sur l'univers du théâtre de la ville, où les groupes perdent leurs espaces de travail. La réflexion s'étend au rôle politique du théâtre et à l'idée de la conscience collective comme quelque chose de dépassé qui doit reprendre de toute urgence.

Mots-clés: théâtre, crise politique, gel de la culture, São Paulo, collectif.

\section{Introdução'}

“Assassinato é a causa de 48\% das mortes de jovens" (Jornal O Estado de S. Paulo, 2017). Esta notícia é recente e inaugurou mais um dia comum na capa de um dos jornais mais importantes do Brasil, juntamente com outras notícias como a do julgamento do caso do atual presidente do país, Michel Temer (Jornal O Estado de S. Paulo, 2017), acusado de estar envolvido num escândalo criminoso, que se comprovado poderá implicar um novo Impeachment no país - o segundo em menos de um ano².

Com base na exposição anterior podemos ter, ainda que de modo bastante geral, um vislumbre do clima que paira sobre a atual situação política do Brasil, que apesar de historicamente marcada por eventos conturbados e obscuros, pode-se dizer que atravessa hoje o momento mais decisivo de sua tão recente democracia.

E, esta crise política, que tem vindo a se agravar nos últimos anos, torna-se cada vez mais evidente para a maioria dos brasileiros, muito através do papel desempenhado pelas redes sociais e os veículos de comunicação, que além de disseminarem de modo veloz as informações (embora muitas delas sejam objeto de manipulação), têm servido também de espaço (ainda que virtual) para debates políticos entre uma parte expressiva da população.

Portanto, torna-se impossível no atual momento, acreditar que a crise atravessada pelo Brasil seja de natureza puramente econômica, como muitos defenderam até o fim do ano de 2016. Pois, diante de um cenário como o de agora, emergem também as polarizações. E, no caso do Brasil a situação

\footnotetext{
1 Este texto foi escrito em 2017 a propósito de alguns acontecimentos que sucederam na cidade de São Paulo (Brasil) nesse ano, relativos à administração do dinheiro público, mais especificamente os recursos destinados ao setor da cultura. Desses eventos que pude acompanhar na época, por ainda residir na cidade, muitos tiveram (e têm tido) consequências políticas conturbadas, tanto no que diz respeito à gestão cultural da cidade e às condições relativas aos grupos de teatro, como também no que se refere à política do país como um todo. Relativamente ao então prefeito, João Dória (mencionado durante o texto) seria importante destacar o fato de Dória ter abandonado o cargo apenas quinze meses após o início de seu mandato, deixando a prefeitura de São Paulo a cargo de seu vice Bruno Covas, com o argumento de que se candidataria a outro cargo, o de governador do estado de São Paulo. Deve-se mencionar ainda, que as eleições para eleger os governadores dos estados brasileiros decorrem no segundo semestre de 2018. Mesmo momento em que o país elegerá também um novo presidente.

2 O primeiro Impeachment aconteceu no dia 31 de Agosto de 2016 quando a presidente Dilma Rousseff acusada por crime de responsabilidade teve seu mandato interrompido. A única vez que isso tinha acontecido no Brasil foi com o presidente Fernando Collor em 1992.
} 
chegou a agravar-se de tal forma, que colocou principalmente em pauta, a urgência de uma educação política que torne possível o verdadeiro exercício e funcionamento da democracia brasileira. Educação esta que, em realidade, nunca existiu.

Assim, ao avaliar a forma de iniciar este texto, que deverá abordar a situação do congelamento recente de uma boa parte dos incentivos destinados à cultura na cidade de São Paulo - em específico o que isto acarreta à situação de alguns grupos de teatro não comercial da cidade - e ao deparar-me com a notícia sobre os jovens, ocorreu-me que talvez fosse interessante trazê-la para o contexto inicial deste texto, antes de falar do tema do teatro, dentro da perspectiva que venho propor. Embora não haja a intenção de explorar os aspectos específicos e que estão contidos na notícia apresentada, espero que à medida que o texto avance, façam-se compreensíveis as motivações para esta exposição inicial.

Antecipo sobre a utilização de fontes e referências para a escrita deste texto, que estas talvez pareçam pouco comuns dentro de um contexto acadêmico e científico. Isto explica-se, em parte, pelo fato de nos últimos anos ter estado muito mais próxima da prática teatral e daquilo que acontecia na cidade, do que propriamente dos estudos acadêmicos. Assim, quando decidi retomar este tipo de estudo, sobretudo para falar de algo tão atual e urgente, a forma mais coerente que me ocorreu foi esta. Pensar através das notícias e estatísticas que correm nos veículos mais populares e acessíveis me interessa, assim como me interessa a abordagem reflexiva acerca de fatos que ainda foram pouco abordados por mais de uma perspectiva. Na mesma via, uma das principais intenções aqui também é de trazer para o ambiente acadêmico, não só o que tem sido construído para constar nas bases bibliográficas, mas também aquilo que pode desaparecer a qualquer momento, como o exercício deste texto, que (apenas) se propõe à tentativa de traçar uma relação entre a situação mais atual do teatro de grupo em São Paulo e a atual conjuntura política e social do país.

Poderíamos inclusive arriscar uma primeira ideia: o teatro é um espelho deste momento. Isto porque não é possível pensarmos em teatro hoje na maior metrópole brasileira - econômica e cultural - sem pensar nas questões que interferem diretamente na realidade da cidade, uma vez que tais questões acarretarão sempre consequências para o fazer teatral e para o restante da cultura. Como é o caso dos investimentos na área da cultura que recentemente sofreram um congelamento de cerca de $43,5 \%$, daquilo que representa menos de $1 \%$ do montante de 54,69 bilhões de reais, o total em dinheiro a ser administrado pela prefeitura da cidade neste ano de 2017 (Rede Brasil Atual, 2017).

Há, no entanto, um consenso geral que corre nos meios culturais e entre artistas, de que o estado crítico da cultura, justificado pela crise econômica que abala o país, tendo entre os principais sintomas o corte de subsídios por parte dos governantes da cidade, resulta, em realidade, de interesses estritamente 
políticos, menos econômicos portanto, como alegam os gestores da cidade. O prefeito João Dória, que assumiu o cargo no início de 2017, em poucos meses de governo, tem se demonstrado bastante inclinado para a privatização de diversos setores, não só o da cultura, como também das áreas da saúde e da educação da cidade de São Paulo. É neste tipo de ação que se baseia de forma bastante assumida, o seu plano de governo (Época Negócios, 2017).

Com base nos parágrafos anteriores é possível que o objetivo primeiro deste texto pareça, por sua vez, o de efetivar uma denúncia aos moldes utilizados para administrar as políticas públicas em São Paulo no que tange a cultura e o teatro. No entanto, gostaria de tornar claro que o texto não tem a intenção de se concentrar no estilo da denúncia, mas de pensar algo que é anterior a esses acontecimentos, que está também implicado na base destes e que diz respeito a todos nós (Melancolia do poder, 2016): a evidente crise do coletivo. Ainda que para falar deste coletivo, a escolha aqui tenha sido a situação atual do teatro na cidade de São Paulo.

Esta breve análise poderá ser vista, portanto, como a construção de uma hipótese (de certa forma bastante pessoal) frente a uma situação específica que se apoia na visão de pensadores contemporâneos como o professor e filósofo brasileiro Vladimir Safatle (Safatle, 2016; Melancolia do poder, 2016) e o pensador esloveno Slajov Zizek (Slajov Zizek, 2013), mas que também se utiliza de um conhecimento empírico adquirido através do contato com certos eventos, alguns deles presenciados, outros mais de perto vividos por mim nestes últimos anos. Para tornar mais claro o percurso pretendido, gostaria também de mencionar: este é um pensamento que tem sido elaborado através do contato com as questões da cidade de São Paulo e do Brasil, mas que ainda é prematuro e, portanto, cheio de lacunas, que espero que possam ser enrijecidas com o tempo, não só por mim, mas por todos aqueles que se interessam pela temática e que se preocupam com os rumos futuros de nossa sociedade e do papel das artes nela. Porque, a "atual crise brasileira”, embora tenha suas especificidades não foi gerada de um dia para o outro e não se resolverá do mesmo modo e por isso, espero que continue a ser objeto de estudo e discussão nas próximas décadas, para que talvez, através desse movimento, possamos encontrar alternativas para mudanças efetivas e, portanto, contínuas (Safatle, 2016).

\section{A crise do coletivo, a crise política e o teatro}

"Em terra em que todos são barões não é possível acordo coletivo durável” (Holanda, 1995: 32)

O Brasil é conhecido sobretudo por suas relações de poder extremas e complexas, oriundas do processo de colonização do país (Holanda, 1995). Sobre esse fato, apesar de possamos pensar o período histórico da colonização 
como distante de nosso tempo e, por esse motivo, distante o suficiente para que esta sociedade pudesse ter superado certas questões, infelizmente isso ainda não foi possível.

O que torna a superação de um modo de organização difícil como a da sociedade brasileira é que o caminho histórico-social do país está impregnado por vícios que se mantêm. Uma estrutura de exploração alicerçada no abismo entre classes (Holanda, 1995), que impede o aparecimento de novos modos de relação. Isto porque, o país vai se mantendo às custas de uma estrutura que foi conservada com o intuito de favorecer uma minoria. Minoria esta que é formada por uma elite branca oligárquica que ainda domina o campo econômico e político do país:

"as constituições feitas para não serem cumpridas, as leis existentes para serem violadas, tudo em proveito de indivíduos e oligarquias, são fenômeno corrente na história da América do Sul. É em vão que os politicos imaginam interessar-se mais pelos princípios do que pelos homens: seus próprios atos representam o desmentido flagrante dessa pretensão” (Holanda, 1995: 182).

Atualmente, tendo em conta os principais eventos políticos que acometeram o país nos últimos anos - como é o caso das manifestações de 2013 que iniciaram um movimento de protestos como há muito não se via, mas ao mesmo tempo deram a ver a ação desmedida e incoerente da polícia militar nesses atos a mando do Estado - veio à tona a fragilidade da democracia brasileira, de existência questionável, dada a forma estranha com que os responsáveis pelo poder público têm agido (ou coagido) com relação à população. Na mesma via, o que as manifestações também fizeram emergir, entre outras questões, foi a dificuldade de se entender, afinal, pelo que se estava lutando e por quem se estava lutando nos tais protestos. Ou seja, a prova de que a participação na vida pública e política está bastante longe da vida das pessoas e que, quando acontece, ainda é por meio de um processo pouco consciente. Pois, como sugere Safatle (Melancolia do poder, 2016), fomos acostumados a pensar que a política é algo degradado, da qual devemos nos proteger, tomar distância e optar sempre pelo que é menos pior do que o pior: a mudança (Melancolia do poder, 2016).

O que faz com que esse quadro se torne mais complicado é que a igualdade de direitos e classes ainda é algo muito distante para o povo brasileiro e num país que vive esse abismo é complicado falar em condições que proporcionem, por exemplo, a existência de um sistema com base na meritocracia. Logo, a situação da maioria dos brasileiros é ainda a de explorados e em favor de uma porcentagem muito pequena da população que detém quase $40 \%$ de toda a 
renda nacional (Jornal O Estado de S. Paulo, 2016). Esta classe é a chamada classe A brasileira e representa apenas $2 \%$ de toda a população. Isso interfere, claro, em todo o tipo de relação seja ela de pequenos, médios, ou grandes poderes. O Brasil é, portanto, um país precário no que tange a esse assunto, não porque possui um sistema de classes, mas sobretudo pela discrepância entre classes (Jornal O Estado de S. Paulo, 2016).

Agora, que tipo de relação é possível estabelecer entre esses fatores e o teatro?

Há quem diga que arte e política não combinam. Para abordar esta questão, gostaria de propor que pensemos num breve e simples exemplo. Recentemente em entrevista ao jornal (Jornal O Estado de S. Paulo, 2017), um ator brasileiro (de novelas), bastante conhecido neste meio e de condição econômica e social estável $^{3}$, relatou o seu descontentamento com a situação da cultura no Brasil e afirmou que dentro dessa situação o teatro era o mais atingido pela falta de investimentos. Ainda na mesma entrevista o ator mencionou o seu descontentamento com a situação confusa da política, mas disse ser um tanto avesso a esse assunto, o que faz com que ele não se disponha, por exemplo, a participar de campanhas ou se colocar politicamente, como outros colegas seus o fazem. Ao fim da entrevista, o ator disse que para ele "a arte e a política são incompatíveis” (Jornal O Estado de S. Paulo, 2017: 32).

A partir deste exemplo, que de maneira proposital é pouco complexo, que aspectos podemos extrair deste tipo de discurso a fim de o aproximar da discussão sobre o teatro e a política? Notemos que se, porventura, o ator não tivesse feito referência à situação calamitosa do país, ou a seus colegas que costumam participar de campanhas, talvez pudéssemos compreender a sua colocação como a de alguém alheio ao discurso político - distante do que acomete a realidade. Porém, no exemplo citado podemos compreender que em seu posicionamento o ator optou (de forma consciente) por colocar-se de maneira contrária à combinação da arte com a política. Ao falar do descontentamento com a situação política, acabou por fazer um discurso de fundo político. Assim, esta, ainda que esteja reduzida ao núcleo da opinião trata-se de uma opinião dada a um jornal e que, sendo assim, nesse momento tornou-se pública. Ou seja, há neste exemplo o dado de que nem sempre chamamos de político a tudo aquilo que tem caráter político, bem como, nem sempre é intencional o fazer político.

Continuando então a pensar acerca da situação atual do teatro e da cultura na cidade de São Paulo, em primeiro lugar é preciso ter em mente o fato de que esta é hoje a maior e mais populosa cidade do país, onde residem a 
maior parte dos investimentos. Por se tratar da cidade mais populosa ${ }^{4}$ (Jornal O Estado de São Paulo, 2016), São Paulo é hoje também o grande centro cultural brasileiro recebendo todo o tipo de expressão artística e de muitas partes do mundo. Porém, como toda a metrópole que cresceu sem planejamento (como é o caso de São Paulo), também aqui se deu o processo de retirada da população do centro para as regiões periféricas mais distantes e menos caras da cidade. Esse processo resultou numa mudança na experiência da cidade também, uma vez que hoje a maior parte da população leva horas para chegar ao trabalho e depois voltar para casa. Nessa aparente desorganização ingênua da cidade a urbanista brasileira Raquel Rolnik $(1995 ; 2015)$ acredita haver na forma de organização dos espaços das cidades brasileiras, uma estratégia política por detrás, pensada para desarticular a população e através de outras medidas acabar com os espaços públicos que sempre foram expressões do corpus coletivo como lugares de debate de assuntos relacionados à vida pública. Este é então, o cenário geral e atual da cidade e é neste cenário que estão também inseridos os grupos que fazem teatro não comercial ${ }^{5}$ em São Paulo.

No que diz respeito ao espaço físico desses grupos, a Especulação Imobiliária é uma medida que pode ser traduzida por: a desapropriação dos espaços ocupados através de uma ação massiva do mercado imobiliário junto aos governantes da cidade. Quando o fazem, aqueles que comandam a Especulação ignoram propositalmente o fato de que esses lugares são onde muitos grupos iniciaram suas pesquisas e puderam trabalhar nos últimos anos, mas infelizmente isso tem acontecido cada vez mais, também agravado pela crise econômica. Muitos grupos de teatro de São Paulo têm tido que desocupar as suas sedes de trabalho porque não conseguem arcar com a especulação (o aumento do aluguel dos espaços) cada vez maior ${ }^{6}$. Outro agravante é que muitas das casas ocupadas pelos grupos participam da história da cidade e quando desapropriadas, normalmente é para serem demolidas e abrir espaço para construção de Shoppings Center's, estacionamentos ou prédios. Com isso, assistimos também ao encerramento de uma série de atividades culturais que antes promoviam movimento nos bairros. Mais uma reorganização do espaço público que terá consequências sobre a vida comum da população, uma vez que muitos desses espaços serviram nesses últimos como espaços de oficinas

4 A cidade de São Paulo conta atualmente com quase 12 milhões de habitantes, quase o dobro da cidade do Rio de Janeiro - a segunda cidade mais populosa do país.

5 Entendemos por teatro comercial, um tipo de teatro que está comprometido com a cultura de entretenimento, com as demandas de produção das instituições e de mercado. Ver vídeos na web: https:// vimeo.com/channels/300618 (Ensaio Aberto, 2011).

6 Alguns dos grupos que já perderam suas sedes de trabalho: Os Fofos encenam (ver: http://www. osfofosencenam.com.br/site/); São Jorge de Variedades (ver em: https://pt-br.facebook.com/pages/category/Performing-Arts/Cia-Sao-Jorge-de-Variedades-1314049828661243/); Teatro de Narradores (ver em: https://www.teatrodenarradores.com/); Núcleo Bartolomeu (ver em: https://www.facebook.com/ nucleobartolomeu/). 
artísticas e apresentações gratuitas para os moradores da região em que ficam situadas essas sedes.

Diante deste quadro, outra questão que surge tem a ver com a escolha dos lugares para apresentação, por parte dos grupos. Que fatores devem ser avaliados na escolha de um lugar para apresentação de uma peça de teatro numa cidade como São Paulo? Em consequência dos fatos apresentados, se um grupo escolhe uma região da cidade no lugar de outra, ou uma instituição, haverá um impacto de ordem política nessa decisão. Haverá impacto na forma como a plateia irá receber o que acontece no palco e que tipo de plateia vai assistir ao trabalho. Ao ensaiar uma peça na qual fui responsável pela função de diretora, eu e o meu grupo de teatro discutimos muito o tema: onde deveríamos apresentá-la? Como a peça falava sobre as relações de dinheiro e poder no Brasil e questionava a dinâmica de servidão com relação ao status que o dinheiro pode ou não oferecer a alguém, não cabia a nós apresentá-la nos palcos tradicionais, ou onde costumam ser apresentadas peças comerciais (nas regiões mais centrais da cidade), ou ainda nos lugares frequentados pela elite. E, embora essa decisão nem sempre seja consciente por parte dos grupos, não deveria ser? Porque a escolha do local de apresentação sempre será uma decisão política. Devemos concordar que, por exemplo, apresentar para um público que está acostumado a frequentar o teatro é distinto de apresentar a pessoas que não têm acesso a esse tipo de programa.

Não por acaso também temos visto do outro lado, as plateias dos teatros manifestarem-se regularmente com gritos de manifestos políticos atualíssimos, como por exemplo, "Fora Temer" e "Descongela a Cultura”. Podemos por um lado medir a relevância dessas manifestações: seu propósito e seu alcance. Por outro, não é possível negar que há algo nessas manifestações em espaços públicos (ou de acesso ao público) que chama a atenção para a urgente discussão do espaço e pensamento coletivos. Não é necessário que os atores emitam discursos de cunho político numa peça de teatro para que as pessoas presentes percebam que aquele é um momento em que artisticamente acontece o debate e que entre outras coisas trata-se de uma experiência coletiva - que pode variar em grau.

Principalmente por estarmos no cerne de um momento instável e de avaliação e revisão de valores que até há pouco tempo pareciam apresentar uma resposta à esperança do povo brasileiro acerca da igualdade de classes - como foi o governo do Partido dos Trabalhadores (PT) para o Brasil e a ideia de uma espécie de "messias brasileiro", o ex-presidente Luiz Inácio Lula da Silva (Lula) - é que as manifestações de todos os lados devem ser notadas. Nas regiões periféricas da cidade de São Paulo há algum tempo muitos artistas dessas zonas da cidade produzem para o coletivo no qual estão inseridos, à luz de uma vivência que não pode ser compreendida internamente, se fora daquela realidade. Somos capazes de problematizar a sociedade e as diferenças entre as classes, 
mas não capazes de traduzir o sentimento de se sentir e estar à margem, a menos que façamos parte dela. Para além disso, sabemos que os sentimentos que nascem das diferenças e da intolerância a estas podem ser perigosos, por um lado, mas extremamente poderosos e potencialmente artísticos, por outro, não nos deixarmos agarrar pela onda promovida pelo poder de um "autoexílio da vida social” (Melancolia do poder, 2016). A exemplo dessas manifestações artísticas temos o Rap e o Hip Hop na cidade de São Paulo, que movimentam milhares de jovens, aproximando-os das questões da comunidade e levando-as ao mundo. Gostaria de trazer aqui a transcrição de parte de uma letra de rap do grupo Racionais MC’s que transmite um pouco desse sentimento e consciência:

"Negro drama/Entre o sucesso e a lama/Dinheiro, problemas/Inveja, luxo, fama/Negro drama/Cabelo crespo/E a pele escura/A ferida, a chaga/À procura da cura/ Negro drama/Tenta ver/E não vê nada/A não ser uma estrela/Longe, meio ofuscada/ Sente o drama/O preço, a cobrança/No amor, no ódio/A insana vingança/Negro drama/Eu sei quem trama/E quem tá comigo/O trauma que eu carrego/Pra não ser mais um preto fodido/O drama da cadeia e favela/Túmulo, sangue/Sirene, choros e vela/Passageiro do Brasil/São Paulo/Agonia que sobrevivem/Em meia às honras e covardias/Periferias, vielas e cortiços/Você deve tá pensando/O que você tem a ver com isso/Desde o início/Por ouro e prata/Olha quem morre/Então veja você quem mata/Recebe o mérito, a farda/Que pratica o mal/Me ver/Pobre, preso ou morto/Já é cultural” (Negro Drama - Nada como um dia após O Outro dia, 2017).

Nem sempre aquilo que é da ordem política foi pensado previamente para tornar-se político. Não é sempre que acessamos essa consciência e é ainda mais complicado ter clareza do que significam e para onde nos levarão os fatos do presente. Com a arte penso que isto ocorre de modo especial, porque ao criarmos estamos de certa forma a abrir espaços, a deixar circular outro tipo de afetos (Safatle, 2016). Lembremos das Vanguardas Artísticas do século XX, que afinal, acabaram por se tornar marcos políticos, apesar de terem surgido por uma insatisfação com relação à forma tradicional de se fazer arte e os limites que esta impunha à arte e aos artistas.

Para o pensador de nosso tempo, Slavoj Zizek, como colocou em entrevista concedida ao programa Roda Viva (2014) no canal brasileiro TV Cultura: a verdadeira luta de um grupo por mudanças sociais deve suceder aos momentos de euforia. Contudo, o que ocorre com os movimentos que exigem a participação intensiva dos grupos que reivindicam mudanças é que normalmente, estes são vencidos pelo cansaço, ou em outras palavras, como diria Safatle 
(Melancolia do poder, 2016) pelo sentimento de melancolia - uma resposta negativa, de descrença com relação à possibilidade de mudança. Este sentimento que torna os sujeitos improdutivos, inativos, sem imaginação e que pode acontecer não apenas com um, ou outro indivíduo, mas se propagar e transformar em patologia social; ao se infiltrar nas pessoas provoca medo e impotência diante das decisões da vida pública e, portanto, política. Não à toa, Safatle propõe a pergunta para pensar o momento atual da sociedade brasileira: "Será que no Brasil não estamos entrando numa era melancólica, nesse tipo de patologia de paralisia social?” (Melancolia do poder, 2016). Mas isto é comum acontecer em diversos momentos da história, assim como é comum e coerente, o sistema operar de forma a suprimir a criatividade, seja ela coletiva ou individual. Por outro lado, cabe aos combativos que se opõem a isso, a tarefa de persistir.

Essa ideia remete, por fim, ao ponto em que queria chegar neste texto e que diz respeito à luta dos grupos de teatro de São Paulo por espaço (não somente físico), que como se constata no momento atual não deveria ter cessado quando estes conquistaram a Lei do Fomento (Lei do Fomento, 2014) em 2002 através do movimento que ficou conhecido como Arte contra a barbárie (Ensaio Aberto, 2011) e que surgiu de uma contestação de ordem política, mas que após a conquista da lei deixou de existir. Por volta do ano de 2000 quando iniciaram as reuniões, naquela época os grupos ainda não tinham ideia da proporção que o movimento viria a agregar e as suas consequências. Não se pensava nem mesmo que a Lei de Fomento (Lei do Fomento, 2014) ao teatro se tornaria a medida mais valiosa dos grupos para a continuidade de suas pesquisas desde aquele momento até o presente. Agora a lei corre o risco de desaparecer sob a nova gestão municipal.

E é exatamente neste ponto em que se insere esta análise: o momento atual como diagnóstico de uma crise do debate coletivo e da ideia de uma preocupação coletiva outrora abandonada. Como afirma Sérgio Carvalho do grupo a Cia do latão (Ensaio Aberto, 2011), o processo de organização dos grupos, uma vez que a Lei de Fomento foi compreendida como algo definitivo, ao contrário do que deveria ser - uma lei provisória que abriria caminho para novas medidas de incentivo à pesquisa e a manutenção dos grupos surgisse - teve o seu fim declarado. O que deveria ter sido percebido como uma pequena vitória foi visto como a vitória em si (Ensaio Aberto, 2011). Conquistada a Lei de Fomento os grupos fecharam-se em núcleos muito restritos. Essa posição agora é reclamada pela realidade e exige novas estratégias e união não só por parte dos grupos do Arte contra a barbárie (Ensaio Aberto, 2011), mas sobretudo dos novos grupos que reivindicam também os seus espaços e novos apoios.

Há um descompasso do coletivo que pode ser percebido também atualmente nas reuniões da classe teatral e na organização de manifestações legítimas em prol de seus direitos. Tem-se notado uma dificuldade extrema de se chegar a um consciente coletivo. Aquele exercício que teve início em 2000 foi 
breve e a chama antes acesa, parece ter se apagado. O que temos agora é que ao se preocuparem em defender o espaço que correm o risco de perder, manifestam-se as mais tristes evidências do que nos falta: pensar uma ética do coletivo e traçar metas em comum. Nesse sentido a política brasileira infelizmente tem servido de espelho para outras relações no âmbito social, como as do teatro. É o inconsciente coletivo, nesse caso, que opera quando usa a política do país como justificativa para suas ações e deixa de se sentir implicado, ele mesmo, nas decisões que são tomadas na cidade. Se investimos nessa forma de pensar veremos que já chegou ao teatro a questão das alianças e dos interesses individuais e que alguém está a ganhar com isso porque ao deixarmos na mão do Estado a decisão, abdicamos da escolha. Ao nos voltarmos para os interesses individuais, perdemos força.

\section{Conclusão}

Desse modo, podemos tentar evidenciar as causas para esta outra crise (a do coletivo) buscando culpados como o sistema, que opera do modo que lhe cabe (o que não quer dizer que seja justo) (Melancolia do poder, 2016); a educação embrutecedora que recebemos (Rancière, 2010) ; as mídias como a televisão; ou o individualismo extremo de nossa era. Só que o teatro em São Paulo agora pede menos por justificativas e mais por atos de irresponsabilidade. Irresponsabilidade porque apesar das dificuldades impostas pelo tempo presente é preciso pensar em um tempo que virá, como ainda não se pensou (Safatle, 2016).

O Brasil só poderá superar a crise política que impera há tanto tempo no país, quando começar a caminhar não no sentido de mais medidas provisórias, mas em mudanças de natureza estrutural. O teatro com seu potencial de unir pessoas, de "capturá-las" do indivíduo para levá-las para perto do debate durante uma vivência que é coletiva, pode ter um papel fundamental nesse sentido, como já teve antes e como mesmo que esparsamente, ainda tem. Assim como a música e os movimentos culturais que surgiram por todo o país durante o período da ditadura militar de 1964.

Parece haver apenas um caminho possível: neste momento é preciso abandonar um tal sentimento de ressentimento com relação à política para que a nova política possa florescer. É preciso resistir a ideia de que a vida política é algo degradado (Melancolia do poder, 2016), não no sentido de manter uma estrutura política segura, mas só conseguiremos alguma mudança efetiva quando abandonarmos qualquer pretensão de segurança (Safatle, 2016). Esse sentimento que circula pelo país numa era pós governo do PT é perigosíssimo para que ideias extremas sejam levadas às últimas consequências, como foi o acontecimento do Impeachment da presidenta Dilma Rousseff que, embora 
não caiba aqui discorrer sobre, foi operado como um golpe, estrategicamente político.

Naquele momento, a presidente estava sozinha e relembrando a peça Vida de Galileu de Bertolt Brecht (1991: 152), que serviu de peça-chave para o desenvolvimento teórico e prático dos principais grupos de teatro de São Paulo: afinal, não há herói maior que a vontade e ação coletiva e esta (Brecht, 1991: 152), por mais heterogênea que seja, deve emergir confrontando sempre o embrutecimento (Rancière, 2010), de um poder que opera através da propagação do sentimento de melancolia nas massas (Melancolia do poder, 2016). Nós só chegamos até aqui na humanidade, juntos. Ou seja, ao dirigirmos pouca atenção à notícia sobre a causa primeira das mortes dos jovens no Brasil, estamos em realidade, dirigindo pouca atenção também a ideia de coletivo.

\section{Referências bibliográficas}

BRECHT, Bertolt (1991), Teatro Completo em 12 volumes (Vol. 6), Rio de Janeiro, Paz e Terra. HOLANDA, Sérgio Buarque de (1995), Raízes do Brasil, São Paulo, Companhia das Letras.

RANCIÈRE, Jacques (2010), O Mestre Ignorante, Cinco lições sobre a emancipação intelectual, Belo Horizonte, Autêntica.

ROLNIK, Raquel (1995), O que é a cidade?, São Paulo, Brasiliense.

ROLNIK, Raquel (2015), Guerra dos lugares. A colonização da terra e da moradia na era das finanças, São Paulo, Boitempo.

SAFATLE, Vladimir (2016), O circuito dos afetos Corpos Políticos, desamparo e o fim do indivíduo, Belo Horizonte, Autêntica.

ZIZEK, Slavoj (2011), Viver no fim dos tempos, Lisboa, Relógio D’Água.

\section{Documentos na Web}

Época Negócios [Online], disponível em: https://epocanegocios.globo.com/Brasil/noticia/2017/04/epoca-negocios-pacote-de-privatizacoes-e-concessoes-de-doria-pode-ter-primeiro-leilao-neste-ano-com-venda-do-anhembi.html [consultado em: 2017].

Jornal O Estado de S. Paulo [Online], disponível em: https://economia.estadao.com.br/noticias/ geral,classe-a-tem-maior-fatia-da-renda-do-pais, 10000007285 [consultado em: 2017].

Jornal O Estado de S. Paulo [Online], disponível em: https://acervo.estadao.com.br/ pagina/\#!/20170606-45157-nac-1-pri-a1-not [consultado em: 2017].

Jornal O Estado de S. Paulo [Online], disponível em: https://acervo.estadao.com.br/ pagina/\#!/20170605-45156-spo-32-cd2-c2-not/busca/Edson+Celulari [consultado em: 2017].

Jornal O Estado de S. Paulo [Online], disponível em: https://sao-paulo.estadao.com.br/noticias/ geral,cidade-de-sao-paulo-chega-a-12-milhoes-de-habitantes,10000072909 [consultado em: 2017].

Rede Brasil Atual [Online], disponível em: https://www.redebrasilatual.com.br/entretenimento/2017/02/artistas-se-mobilizam-contra-cortes-de-doria-no-orcamento-da-cultura [consultado em: 2017]. 
Lei de Fomento [Online], disponível em: http://www.planalto.gov.br/ccivil_03/_ato20112014/2014/lei/l13019.htm [consultado em: 2017]

\section{Vídeos na Web}

Institutocpfl. (2016, Agosto 23), Melancolia do poder, com Vladimir Safatle (versão completa). Disponível em: http://www.institutocpfl.org.br/2016/08/23/ melancolia-do-poder-com-vladimir-safatle-versao-completa/.

YouTube. (2017, Março 6), Negro Drama - Nada como um dia após O Outro dia (Chora Agora). Disponível em: https://www.youtube.com/watch?v=u4lcUooNNLY.

Fundação Padre Anchieta (2013, Julho 8), Slavoj Žižek, Disponível em: http://tvcultura.com.br/ videos/13430_slavoj-zizek-08-07-2013.html.

Vimeo. (2011), Ensaio Aberto, Disponível em: https://vimeo.com/channels/300618.

\section{Páginas dos grupos de teatro citados que perderam suas sedes de trabalho}

Os Fofos encenam [Online], disponível em: http://www.osfofosencenam.com.br/site/ [consultado em: 2017].

Cia São Jorge de Variedade [Online], disponível em: https://pt-br.facebook.com/pages/category/ Performing-Arts/Cia-Sao-Jorge-de-Variedades-1314049828661243/ [consultado em: 2017].

Teatro dos Narradores [Online], disponível em: https://www.teatrodenarradores.com/ [consultado em: 2017].

Núcleo Bartolomeu [Online], disponível em: https://www.facebook.com/nucleobartolomeu/ [consultado em: 2017]. 